\title{
Adoption of Four Crops Cultivation Pattern by the Farmers
}

\author{
Pallab Goswami $^{* 1}$, Saiful Huda ${ }^{\# 2}$, Md. Abu Sayed Mondol ${ }^{\# 3}$ \\ *MS Student, "Professor, Department of Agricultural Extension, Hajee Mohammad Danesh Science and \\ Technology University, Dinajpur-5200, Bangladesh
}

\begin{abstract}
The main purpose of the study was to determine the extent of adoption of four crops cultivation pattern by the farmers, to determine the factors influenced by the farmers in adopting four crops cultivation pattern and to explore the relationships between nine selected characteristics of the farmers with their adoption of four crops cultivation pattern. Data were collected from a sample of 104 farmers (out of 400) selected by simple random sampling procedure from Baragoan and Nargun union under Thakurgaon Sadar upazila of Thakurgaon district. A pretested and structured interview schedule was used to collect data from the respondents during 15 September to 15 October, 2016. The highest proportion (75.0 percent) of the farmers had medium adoption of four crops cultivation pattern, while 23.1 and 1.9 percent of them had high and low adoption of four crops cultivation pattern respectively. The major factor influenced the farmers were "four crop cultivation is profitable", followed by "four crop cultivation is very important for food security." Government subsidies are available when faced with the loss of crops, timely receipt of NGO loans and provides food for cattle had ranked last three positions. Correlation analyses indicated that among nine selected characteristics education, annual income, training received, organizational participation, extension media contact and agricultural knowledge had positive significant relationships with their adoption of four crops cultivation pattern. However, age, family size, and farm size of the farmers had no significant relationships with their adoption of four crops cultivation pattern.
\end{abstract}

\section{Keywords}

Adoption, four crops, cultivation pattern, farmers, factors.

\section{INTRODUCTION}

Bangladesh is predominantly an agricultural country comprising 147,610 square kilometres (56,990 sq $\mathrm{mi})$ and extends 820 kilometres $(510 \mathrm{mi})$ north to south and 600 kilometres $(370 \mathrm{mi})$ east to west with an estimated population is 162.72 million [1].The population density of Bangladesh is 1103 persons per square kilometer and per capita income is about US dollar 1,909 [2].

Bangladesh is highly dependent on its rural economy as 80 percent people live in rural areas [3]. Agriculture remains the major pillars of the Bangladesh national economy. It plays a vital role in ensuring food security, rising standard of living and increase export earnings. Agriculture and environment have a close relationship and interact with each other. The output prices from agriculture have been found to contribute 23.50 percent to the GDP in which 13.44 percent comes from crops, 1.90 percent from forestry, 2.93 percent from livestock and 5.23 percent from fisheries [4].

Four crops cultivation pattern is the judicious utilization of time and space to increase the total crop output per unit area. This cropping pattern, evolved and introduced by RDRS Bangladesh, a non-government organization, has been helping the farmers in getting four crops annually on the same land contributing substantially to increase crop intensity and food production. It is a very good practice to increase total crop yield balancing the nutritional requirements, higher monetary return, greater resource utilization and to fulfill the diversified needs of the farmers.

Food insecurity and unemployment of farm workers in September-October can be mitigated by up-scaling the production of short duration aman rice (Var. BU Dhan 1, BRRI Dhan 56, BINA Dhan 7) as it can be harvested by October. It is evident and popularized in some areas of northern Bangladesh through the preliminary research and development works done with the financial assistance of Krishi Gobeshona Foundation (KGF) from May 
2009 - April 2011. Similar changes in other parts of northern region will not only ensure food security but also enhance system productivity as it facilitates timely planting of winter potato or wheat after the rice harvest [5]. However, this practice requires further testing and validation under specific micro-environments.

High intensive four crops in sequence aman (early- potato or mustard-mungbean -aus (early) was tested against farmers cropping pattern aman (late)-potato-boro (late) in northern region of Bangladesh to increase cropping intensity and productivity with minimum resource use and creation of employment during joblessness time. While in central part, boro - aus (early) - aman (early) was tested against farmers cropping pattern boro fallow - aman to increase cropping intensity and productivity in rice-based cropping system. Economic analysis showed that the alternate cropping patterns are more economical than the crops grown in the existing cropping pattern. Among the four crops grown in sequence, potato contributed the highest economic return although it required highest investment in crop cultivation. Gross return in potato of alternate cropping pattern (Tk. 300188 $\mathrm{ha}^{-1}$ ) was found almost double than potato in farmers cropping pattern (Tk. $145661 \mathrm{ha}^{-1}$ ) mostly because of higher market price of early potato than late harvested potato of farmers cropping pattern [6].

Besides, growing of boro after potato is becoming popular in sandy loam soil of northern region. Cultivation of boro rice in upland ecosystem is very much input intensive especially huge amount of ground water withdrawal is required throughout the growing season. Alternately Pariza, a short duration rice and short duration mungbean can easily be grown after harvesting of potato with minimal or without withdrawing ground water for irrigation. Thus, inclusion and up-scaling of short duration crops varieties (rice and mungbean) in the cultivation pattern would increase cropping intensity, system productivity and employment opportunity in northern Bangladesh with minimum use of valuable resources including ground water and chemical fertilizers. So, cultivation of four crops is very essential to get more output from a same land. in view of this context, the study was conducted with the following objectives; i) to determine some selected characteristics of the farmers practicing four crops cultivation pattern; ii) to determine the extent of adoption of four crops cultivation pattern by the farmers; iii) to determine the factors influenced by the farmers in adopting four crops cultivation pattern; and iv) to determine the relationship between the selected characteristics of the farmers and their extent of adoption of four crops cultivation pattern.

\section{Locale of the Study, Population and Sample}

\section{METHODOLOGY}

The study was conducted in two union of Thakurgaon Sadar upazila namely Baragoan and Nargun under Thakurgaon district. The farmers of Baragoan and Nargun union are cultivating four crops that are supervised by a Non-Government Organizations named Agri and Research Foundation (ARF) and support by RDRS. An updated list of 400 farmers was collected from RDRS office record who followed four crops cultivation pattern. Out of them a sample of 104 farmers (26 percent) was selected by random sampling method.

\section{Measurement of Variables}

The nine characteristics of the respondents namely age, education, family size, farm size, annual income, training received, organizational participation, extension media contact and agricultural knowledge constituted the selected characteristics of this study. These selected characteristics were measured by appropriate measurement techniques. In this study adoption of four crops cultivation pattern by the farmers was the focus issue. The measurement procedure of the focus issue discussed below: It was measured by the following formula of a particular year [7]:

$$
\text { Adoption of four crops cultivation pattern }=\frac{\text { Land under four crops cultivation }}{\text { Potential area for four crops cultivation }} \times 100
$$

Adoption of four crops cultivation pattern by the farmers was measured for four years $(2012,2013,2014$, and 2015). Finally, adoption of four crops cultivation pattern was measured by average of four years as follows:

$$
\text { Adoption of four crops cultivation pattern }=\frac{\text { Adoption of four crops cultivation pattern for } 4 \text { years }}{4}
$$


Thus, adoption of four crops cultivation pattern by the farmers ranged from 0 to 100 . Where ' 0 ' indicates no. adoption of four crops cultivation pattern and ' 100 ' indicates very high adoption four crops cultivation pattern.

Fourteen factors were selected for the study which influences adoption of four crops cultivation pattern. The respondents were asked to response on four alternatives responses as 'not at all', 'low', 'medium' and 'high' for each of fourteen selected factors. Scores were assigned to those alternative responses as $0,1,2$ and 3 respectively. Thus, the possible factor influencing score of the respondents could range from 0 to 42 , where 0 indicating no factor influencing while 42 indicating high factor influencing in four crops cultivation by the farmers. To ascertain the comparison among the factors, Factor Influencing Index (FII) was computed by using the following formula:

$\mathrm{FII}=\mathrm{Fh} \times 3+\mathrm{Fm} \times 2+\mathrm{Fl} \times 1+\mathrm{Fn} \times 0$

Where,

FII = Factor Influencing Index

$\mathrm{Fh}=$ Number of respondents influenced 'high'

$\mathrm{Fm}=$ Number of respondents influenced 'medium'

$\mathrm{Fl}=$ Number of respondents influenced 'low'

$\mathrm{Fn}=$ Number of respondents influenced 'not at all'

Thus FII for a particular factor could range from ' 0 ' to ' 312 ', while ' 0 ' indicating no factor influenced and ' 312 ' indicating highest factor influenced. FII for all the factors were determined. Finally a rank order was made on the basis of FII.

\section{Data Collection and Statistical Analysis}

Data were collected during the period from 15 September to 15 October, 2016 by using the pretested questionnaire. Qualitative data were converted in quantitative data by means of suitable scoring technique whenever necessary. The SPSS computer program was used for analysing the data. Pearson's Product Moment Correlation Coefficient ( $r$ ) was used for testing the relationships between the concerned variables.

Selected Characteristics of the Farmers

\section{RESULTS AND DISCUSSION}

The nine characteristics of the farmers were selected characteristics of this study. Their main features and categorization are presented in Table 1.

Table 1 Main Features and Categorization of the Farmers (N=104)

\begin{tabular}{|c|c|c|c|c|c|c|c|c|}
\hline \multirow{2}{*}{ Characteristics } & \multirow{2}{*}{$\begin{array}{l}\text { Scoring } \\
\text { method }\end{array}$} & \multicolumn{2}{|c|}{ Range } & \multirow{2}{*}{ Categories } & \multicolumn{2}{|c|}{ Respondents } & \multirow{2}{*}{ Mean } & \multirow{2}{*}{ SD } \\
\hline & & Possible & Observed & & No. & Percent & & \\
\hline \multirow{3}{*}{ Age } & \multirow{3}{*}{ No. of year } & \multirow{3}{*}{ Unknown } & \multirow{3}{*}{$23-65$} & Young (18-35) & 52 & 50.0 & \multirow{3}{*}{38.21} & \multirow{3}{*}{9.72} \\
\hline & & & & Middle (36-50) & 40 & 38.5 & & \\
\hline & & & & Old $(>50)$ & 12 & 11.5 & & \\
\hline \multirow{4}{*}{ Education } & \multirow{4}{*}{$\begin{array}{c}\text { Year of } \\
\text { schooling }\end{array}$} & \multirow{4}{*}{ Unknown } & \multirow{4}{*}{$0.5-16$} & Can sign only (0.5) & 18 & 17.3 & \multirow{4}{*}{7.79} & \multirow{4}{*}{4.36} \\
\hline & & & & Primary level (1-5) & 17 & 16.3 & & \\
\hline & & & & Secondary level ( 6-10) & 50 & 48.1 & & \\
\hline & & & & $\begin{array}{l}\text { Above secondary level } \\
(>10)\end{array}$ & 19 & 18.3 & & \\
\hline \multirow{3}{*}{ Family size } & \multirow{3}{*}{$\begin{array}{l}\text { No. of } \\
\text { members }\end{array}$} & \multirow{3}{*}{ Unknown } & \multirow{3}{*}{$2-8$} & Small $(\leq 4)$ & 28 & 26.9 & \multirow{3}{*}{4.26} & \multirow{3}{*}{1.24} \\
\hline & & & & Medium ( 5-6) & 71 & 68.3 & & \\
\hline & & & & Large $(>6)$ & 5 & 4.8 & & \\
\hline
\end{tabular}




\begin{tabular}{|c|c|c|c|c|c|c|c|c|}
\hline \multirow{3}{*}{ Farm size } & \multirow{3}{*}{ Hectare } & \multirow{3}{*}{ Unknown } & \multirow{3}{*}{$0.2-3.24$} & Small (0.21-1.0) & 67 & 64.4 & \multirow{3}{*}{0.98} & \multirow{3}{*}{0.73} \\
\hline & & & & Medium (1.01-3.0) & 32 & 30.8 & & \\
\hline & & & & Large $(>3.0)$ & 5 & 4.8 & & \\
\hline \multirow{3}{*}{ Annual income } & \multirow{3}{*}{ ('000’ Tk.) } & \multirow{3}{*}{ Unknown } & \multirow{3}{*}{$\begin{array}{l}40.0- \\
500.0\end{array}$} & Low $(\leq 55)$ & 8 & 7.7 & \multirow{3}{*}{174.42} & \multirow{3}{*}{119.09} \\
\hline & & & & Medium ( 55.01-295) & 79 & 76.0 & & \\
\hline & & & & High $(>295$ ) & 17 & 16.3 & & \\
\hline \multirow{4}{*}{ Training received } & \multirow{4}{*}{ Days } & \multirow{4}{*}{ Unknown } & \multirow{4}{*}{$0-90$} & No $(0)$ & 4 & 3.8 & \multirow{4}{*}{7.36} & \multirow{4}{*}{11.76} \\
\hline & & & & Low $(\leq 3)$ & 28 & 26.9 & & \\
\hline & & & & Medium (4-7) & 45 & 43.3 & & \\
\hline & & & & $\operatorname{High}(>7)$ & 27 & 26.0 & & \\
\hline \multirow{3}{*}{$\begin{array}{l}\text { Organizational } \\
\text { participation }\end{array}$} & \multirow{3}{*}{ Score } & \multirow{3}{*}{$0-24$} & \multirow{3}{*}{$1-6$} & Low $(\leq 8)$ & 51 & 49.0 & \multirow{3}{*}{1.83} & \multirow{3}{*}{1.07} \\
\hline & & & & Medium (9-17) & 48 & 46.2 & & \\
\hline & & & & High $(>17)$ & 5 & 4.8 & & \\
\hline \multirow{3}{*}{$\begin{array}{l}\text { Extension media } \\
\text { contact }\end{array}$} & \multirow{3}{*}{ Score } & \multirow{3}{*}{$0-30$} & \multirow{3}{*}{$2-24$} & Low $(\leq 10)$ & 17 & 16.3 & \multirow{3}{*}{12.08} & \multirow{3}{*}{4.17} \\
\hline & & & & Medium (11-20) & 73 & 70.2 & & \\
\hline & & & & High $(>20)$ & 14 & 13.5 & & \\
\hline \multirow{3}{*}{$\begin{array}{l}\text { Agricultural } \\
\text { Knowledge }\end{array}$} & \multirow{3}{*}{ Score } & \multirow{3}{*}{$0-26$} & \multirow{3}{*}{$4-20$} & Low $(\leq 8)$ & 30 & 28.8 & \multirow{3}{*}{11.21} & \\
\hline & & & & Medium (9-17) & 57 & 54.8 & & 3.57 \\
\hline & & & & High $(>17)$ & 17 & 16.4 & & \\
\hline
\end{tabular}

The observed age of the farmers ranged from 23 to 65 years with a mean of 38.21 and more than four-fifths ( 88.5 percent) of the farmers were young to middle aged. That means young to middle-aged farmers in the study area were largely adoption of four crops. Ruma $(2014){ }^{[8]}$ also found similar findings in her study. The education score of the farmers ranged from 0.5 to 16 with the mean value of 7.79 and the highest proportion (48.1percent) of the farmers had education up to secondary level. Khanom (2014) ${ }^{[9]}$ also found similar findings in her study. The overwhelming majority (66.4 percent) of the farmers had education ranging from secondary to above secondary level. The family size of the farmers ranged from 2 to 8 having mean value of 4.26 and overwhelming of the farmers 68.3 percent have medium sized family. Khanom (2014) ${ }^{[9]}$ also found similar findings in her study. The farm size of the farmers ranged from 0.2 to 3.24 and the mean was 0.98 and data showed that about three-fourths (64.4 percent) of the farmers were under small farm size category. Overwhelming majority $(95.20 \%)$ of the farmers had small to medium farm size. Hossain et al. $(2011)^{[10]}$ also found similar findings in his study. Annual income of the farmers ranged from 40.0 to 500.0, the mean being 174.42 thousand tk. and the majority (76.0 percent) of the farmers had medium income compared to 16.3 percent of them having high income and only 7.7 percent had low income. Ekram $(2014)^{[11]}$ also found similar findings in his study. Thus, the huge majority ( 92.3 percent) of the farmers had medium to high income. The observed training received scores of the respondents ranged from 0 to 90 with an average of 7.36 and majority (43.3 percent) of the farmers had medium training received. This finding was supported by Ruma (2014) ${ }^{[8]}$. Organizational participation score of the respondents ranged from 1 to 6 and with a mean of 1.83 and the findings revealed that about half (49.0 percent) of the respondents had low participation in organization. Ruma (2014) ${ }^{[8]}$ also find similar findings in her study. Overwhelming majority (95.2 percent) of the farmers had low to medium organizational participation. The observed extension media contact scores of the respondents ranged from 2 to 24 with average 
was 12.08 and overwhelming majority ( 86.5 percent) of the farmers had low to medium extension contact. Khanom (2014) ${ }^{[9]}$ also found similar findings in her study. Agricultural knowledge scores could theoretically range from 0 to 26 with the mean being 11.21 and slightly more than half (54.8 percent) farmers' possessed medium knowledge. This finding was supported by Ruma (2014) ${ }^{[8]}$. Major proportion (71.2 percent) of the farmers had medium to high knowledge on various aspects of agricultural system.

\section{Adoption of Four Crops Cultivation Pattern by the Farmers}

The observed adoption of four crops cultivation pattern by the farmer's scores ranged from 29.17 to 100.00 against the possible range of 0 to 100 with an average of 58.49 and standard deviation of 13.23. On the basis of their four crops cultivation pattern scores, the farmers were classified into three categories as: "low adoption" (0-33.33), "medium adoption" (33.34 -66.67) and "high adoption" ( $>66.67)$ [7]. The four crops cultivation pattern of the farmers according to their extent of adoption four crops cultivation pattern scores is shown in Table 2.

The Table 2 shows that highest proportion (75.0 percent) of the farmers had medium adoption of four crops cultivation pattern, while 23.1 and 1.9 percent of them had high and low adoption of four crops cultivation pattern respectively. It means that majority (98.1) of the respondents belonged to medium to high adoption of four crops cultivation pattern.

Table 2 Adoption of Four Crops Cultivation Pattern by the Farmers

\begin{tabular}{|c|c|c|c|c|c|c|}
\hline \multirow{2}{*}{ Categories } & \multicolumn{2}{|c|}{ Farmers } & \multirow{2}{*}{$\begin{array}{c}\text { Observed } \\
\text { range }\end{array}$} & $\begin{array}{c}\text { Possible } \\
\text { range }\end{array}$ & Mean & SD \\
\cline { 2 - 3 } & Number & Percent & & & & \\
\hline Low adoption (0-33.33) & 2 & 1.9 & & \multirow{2}{*}{58.49} & 13.23 \\
\cline { 1 - 3 } Medium adoption (33.34-66.67) & 78 & 75.0 & \multirow{2}{*}{$29.17-100$} & $0-100$ & & \\
\hline High adoption (> 66.67) & 24 & 23.1 & & & \\
\hline Total & 104 & 100.00 & & & \\
\hline
\end{tabular}

The result might be due to that adoption of four crops cultivation pattern by the farmers is not up to the mark for getting the potential benefits from four crops cultivation. So, it is revealed that among the farmers of the study area the adoption scenario is moderate. Most of the cultivation area has been captured by rice to meet the demand of food for the ever increasing people. Farmers always want to ensure their food security first then there turn from their cultivation. Farm area is decreasing day by day due to over population. Alternate cropping pattern is essential to meet the demand of food which leads the famers of the study area switch to adopt four crops cultivation. Similar type of adoption was found by Kabir ${ }^{[12]}$ in adoption of modern jute cultivation practices.

\section{Factors Influencing Adoption of Four Crops Cultivation Pattern}

The observed factors influencing scores of the farmers ranged from 15 to 34 against the possible factors influencing scores were 0 to 42 with an average of 26.09 and the standard deviation 3.99. On the basis of factors influencing scores, the growers were distributed into three categories as low $(\leq 22)$, medium $(23-30)$ and high $(>$ 30) (Fig. 1).

Data contained in the Fig. 1 reveals that the highest proportion $(69.2$ percent $)$ of the farmers had medium factors influencing as compared to 15.4 percent low and 15.4 percent had high factors influencing regarding the adoption of four crops cultivation pattern. The findings of the study indicated that overwhelming majority (84.6 percent) of the respondents had medium to high factors influenced in four crops cultivation pattern. The findings revealed that farmers were moderate influenced by the factors in four crops cultivation pattern. This may helps to increase the rate of adoption of four crops cultivation pattern. 


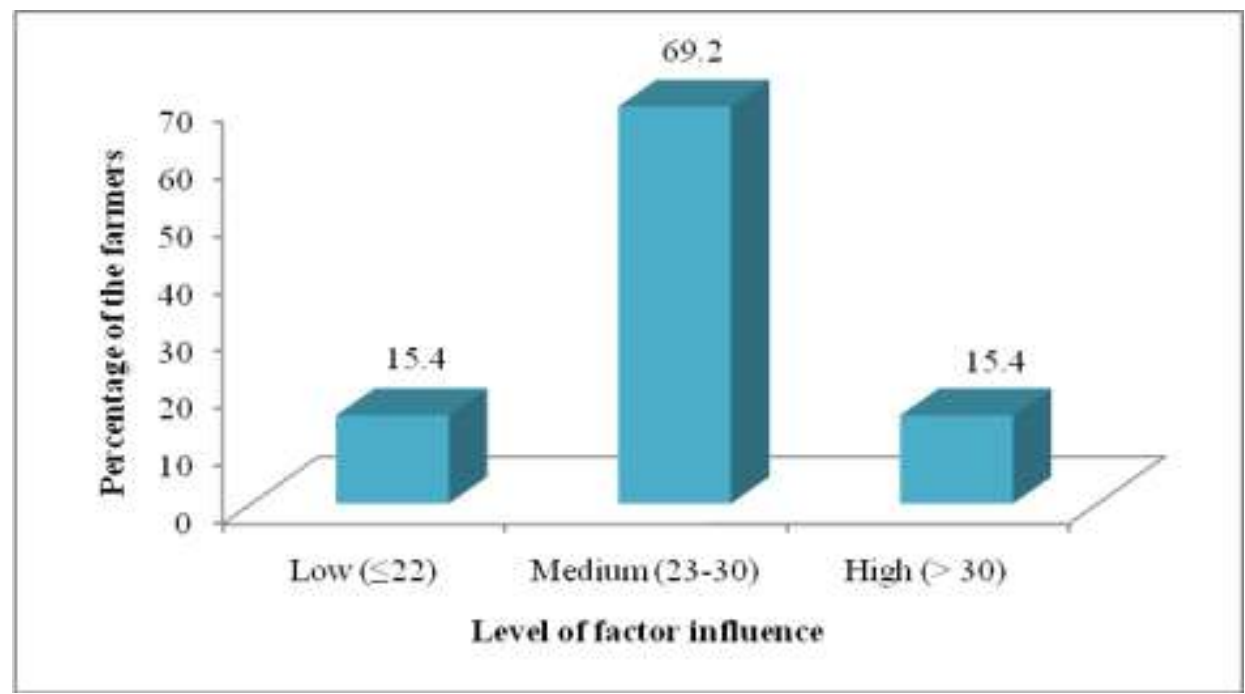

Fig. 1 Distribution of the farmers according to their factor influence

\section{Rank Order of Factors Influencing the Farmers for Adoption of Four Crop Cultivation Pattern}

The farmers were asked to mention the specific factors concerned by them in four crops. The factors influence identified by the farmers is listed below according to their importance (Table 3). The total Factors Influencing Index (FII) ranged from 98 to 237 with possible range of 0 to 312 (Table 3). Data presented above showed that the extent of adoption of four crops cultivation pattern was mostly influenced by four crop cultivation is profitable followed by four crop cultivation is very important for food security and suggestions from extension personnel. This is due to that farmers were more benefitted for cultivation of four crops. They utilize their land properly and their demand is fulfilled by cultivation of four crops.

Table 3 Rank Order of Factor Influencing Farmer's Adoption of Four Crops Cultivation Pattern

\begin{tabular}{|c|c|c|c|c|c|c|}
\hline \multirow{2}{*}{ Description of factors } & \multicolumn{4}{|c|}{$\begin{array}{c}\text { Number of respondents influenced with } \\
\text { extent of adoption }\end{array}$} & \multirow{2}{*}{$\begin{array}{l}\text { Factors } \\
\text { Influencing } \\
\text { Index (FII) }\end{array}$} & \multirow{2}{*}{$\begin{array}{l}\text { Rank } \\
\text { Order }\end{array}$} \\
\hline & $\begin{array}{l}\text { Not at } \\
\text { all }\end{array}$ & Low & Medium & High & & \\
\hline Four crop cultivation is profitable & 0 & 7 & 61 & 36 & 237 & 1 \\
\hline $\begin{array}{l}\text { Four crop cultivation is very important for } \\
\text { food security }\end{array}$ & 0 & 6 & 72 & 26 & 228 & 2 \\
\hline Increase employment opportunity & 0 & 23 & 55 & 26 & 221 & 4 \\
\hline $\begin{array}{l}\text { Four crop cultivation aims at improving the } \\
\text { productivity of the farmers }\end{array}$ & 0 & 17 & 67 & 20 & 211 & 6.5 \\
\hline Use of fallow land & 3 & 31 & 47 & 23 & 194 & 11 \\
\hline $\begin{array}{l}\text { Agricultural production (crop) has } \\
\text { considerably increased }\end{array}$ & 0 & 19 & 64 & 21 & 210 & 8 \\
\hline $\begin{array}{l}\text { My family has a reputation to adopt four } \\
\text { crops cultivation pattern }\end{array}$ & 6 & 19 & 44 & 35 & 212 & 5 \\
\hline $\begin{array}{l}\text { My neighbors frequently visit my house and } \\
\text { advise me to adopt four crops cultivation } \\
\text { pattern }\end{array}$ & 1 & 24 & 53 & 26 & 208 & 9 \\
\hline Fulfill nutritional demand & 0 & 21 & 59 & 24 & 211 & 6.5 \\
\hline
\end{tabular}




\begin{tabular}{|l|c|c|c|c|c|c|}
\hline Suggestions from extension personnel & 5 & 16 & 39 & 44 & 226 & 3 \\
\hline Helps to remove poverty & 2 & 24 & 61 & 17 & 197 & 10 \\
\hline $\begin{array}{l}\text { Government subsidies are available when } \\
\text { faced with the loss of crops }\end{array}$ & 53 & 37 & 11 & 13 & 98 & 14 \\
\hline Timely receipt of NGO loans & 26 & 20 & 51 & 7 & 143 & 13 \\
\hline Provides food for cattle & 6 & 44 & 48 & 6 & 158 \\
\hline
\end{tabular}

Government subsidies are available when faced with the loss of crops, timely receipt of NGO loans and provides food for cattle had ranked last three positions.

\section{Relationship between the Selected Characteristics of the Farmers and their Adoption of Four Crops} Cultivation Pattern

Table 4 Relationship between Selected Characteristics and Focus Issue

\begin{tabular}{|c|l|c|}
\hline \multirow{4}{*}{\begin{tabular}{c} 
Dependent variable \\
\multirow{4}{*}{$\begin{array}{c}\text { Adoption of four crops } \\
\text { cultivation pattern by the } \\
\text { farmers }\end{array}$}
\end{tabular}} & Selected Characteristics & $\begin{array}{c}\text { Computed r-value with } \\
102 \text { d.f. }\end{array}$ \\
\cline { 2 - 3 } & Age & 0.166 \\
\cline { 2 - 3 } & Education & $0.235^{*}$ \\
\cline { 2 - 3 } & Family size & 0.085 \\
\cline { 2 - 3 } & Frnual income & 0.026 \\
\cline { 2 - 3 } & Training received & $0.256^{* *}$ \\
\cline { 2 - 3 } & Organizational participation & $0.196^{*}$ \\
\cline { 2 - 3 } & Extension media contact & $0.225^{*}$ \\
\cline { 2 - 3 } & Agricultural knowledge & $0.340^{* *}$ \\
\hline
\end{tabular}

Coefficient of correlation was computed in order to explore the relationship between the selected characteristics of the farmers and their adoption of four crops cultivation pattern. Correlation analyses indicated that education of the farmers had a significant positive relationship with their adoption of four crops cultivation pattern. Similar findings were also observed by Mou (2015) ${ }^{[13]}$, Hasan $(2015)^{[14]}$, Singh (2010) ${ }^{[15]}$, and Rao and Singh (2014) [16]. Annual income of the farmers had a significant positive relationship with their adoption of four crops cultivation pattern. Similar findings were also observed by Mou (2015) ${ }^{[13]}$, Mehta and Sonawane (2012) ${ }^{[17]}$, Chouhan and Singh (2013) ${ }^{[18]}$, Rao and Singh (2014) ${ }^{[16]}$ and Deshmukh and Bariya (2014) ${ }^{[19]}$. Above findings revealed that training received of the farmers had a significant positive relationship with their adoption of four crops cultivation pattern. It means that adoption of four crops cultivation pattern as increased with the increase of training received. The reason might be that after completion of a successful training, farmers are expected to be aware of the benefits of four crops cultivation pattern and also have enough knowledge about the cultivation process of different crops. Mou (2015) ${ }^{[13]}$, Kabir (2015) ${ }^{[20]}$ and Rahman (2010) ${ }^{[21]}$ also found similar findings in their studies. Organizational participation of the farmers had a significant positive relationship with their adoption of four crops cultivation pattern. It means that farmers with highly organizational participation were more likely to have more adoption. Haque (1984) ${ }^{[22]}$, Mohammad (1974) ${ }^{[23]}$ also found the similar results in their studies. Extension media contact of the farmers had a significant positive relationship with their adoption of four crops cultivation pattern. That is if the extension media contact is higher, the adoption of four crops cultivation pattern would also be higher. The finding is quite logical because extension contact makes the farmers innovative and strengthens their basic knowledge. So, high media contact farmers are supposed to be 
highly eager to adopt four crops cultivation. Similar findings were also observed by Hasan (2015) ${ }^{[14]}$, Singh (2010) ${ }^{[15]}$, Rao and Singh (2014) ${ }^{[16]}$ and Deshmukh and Bariya (2014) ${ }^{[19]}$. Agricultural knowledge of the farmers had a significant positive relationship with their adoption of four crops cultivation pattern. It means that adoption of four crops cultivation pattern as increased with the increase of agricultural knowledge. The reason might be that with the increase of agricultural knowledge become aware of the benefits of four crops cultivation pattern. Similar findings were also observed by Kabir (2015) ${ }^{[20]}$, Singh (2010) ${ }^{[15]}$, and Chouhan and Singh (2013) ${ }^{[18]}$. Age, family size, and farm size of the farmers had no significant relationship in adoption of four crops cultivation pattern. These indicate that adoption of four crops cultivation pattern and above characteristics of the farmers are independent to each other.

\section{CONCLUSIONS}

Majority (75.0 percent) of the farmers had medium adoption of four crops cultivation pattern. The result might be due to that adoption of four crops cultivation pattern by the farmers is not up to the mark for getting the potential benefits from four crops cultivation. Overwhelming majority ( 86.5 percent) of the farmers had low to medium extension media contact, while there had a positive significant relationship between extension media contact and adoption four crops cultivation pattern. Therefore, it might be concluded that, low extension media contact farmers adopted less four crops cultivation and the farmers with high extension media contact showed high adoption of four crops cultivation pattern. Major proportion (71.2 percent) of the farmers had medium to high agricultural knowledge and there had a positive significant relationship between agricultural knowledge and adoption of four crops cultivation pattern. Therefore, it may be concluded that, farmers who had higher agricultural knowledge were adopted four crops cultivation more easily in the study area. The highest proportion (69.2 percent) of the farmers had medium factors influencing four crops cultivation pattern. This might be concluded farmers are influenced by several factors during adoption of four crops cultivation pattern which are to be taken into consideration in the study area. The extent of adoption of four crops cultivation pattern was mostly influenced by four crop cultivation is profitable followed by four crop cultivation is very important for food security and suggestions from extension personnel. Government subsidies are available when faced with the loss of crops, timely receipt of NGO loans and provides food for cattle had ranked last three positions

\section{ACKNOWLEDGEMENTS}

The author deeply acknowledges the cooperation and sincere help of the concerned personnel of RDRS in the research working area.

\section{REFERENCES}

[1] Countrymeters. A online portal to estimate the population in world, 2016. Retrieved from:http://countrymeters.info/en/Bangladesh

[2] BBS. Statistical Year Book of Bangladesh. Bangladesh Bureau of Statistics. Statistics Division, Ministry of Planning, Government of the People's Republic of Bangladesh, 2019.

[3] BBS. Yearbook of Agricultural Statistics of Bangladesh. Bangladesh Bureau of Statistics, Statistical division, Ministry of Planning, Government of the People's Republic of Bangladesh, Dhaka, 2016.

[4] BBS. Statistical Year Book of Bangladesh. Bangladesh Bureau of Statistics. Statistics Division, Ministry of Planning, Government of the People's Republic of Bangladesh, 2014.

[5] Haque. Impact of rice-wheat/potato-mungbean cropping system on farmers' employment opportunity, food security and livelihood in selected monga prone areas in northern districts of Bangladesh. Annual Report submitted to Krishi Gobeshona Foundation, BARC campus, Farmgate, Dhaka, 2010.

[6] Rashid, M. M. and M. M. Haque. Good Practices, New Cropping Pattern Gives Four Crops Annually. Annual Reports, RDRS, Bangladesh, 2016 .

[7] Islam, H. M. S. Adoption of Mixed Cropping in Rabi Season by The Farmers of Madaripur Sadar Upazila. M. S. Thesis (Agricultural Extension and Information System), SAU, Dhaka, 2007.

[8] Ruma, N. N. Use of Mass Media by the Farmers in Adoption of Rice Production Technologies in Bera Upazila of Pabna District. M.S. (AEIS) Thesis, Department of Agricultural Extension and Information System, Sher-E-Bangla Agricultural University, Dhaka, 2014.

[9] Khanom, M. Z. Adoption of Improved Practices in Litchi Cultivation by the Litchi Growers of Dinajpur District. M.S. Thesis. Department of Agricultural Extension, Hajee Mohammad Danes science and Technology University, Dinajpur, 2014. 
[10] Hossain, K. Z., M. R. Islam, M. H. Bhuiyan, M. A. Wazad and M. M. Rahman. Farmers' communication behavior in receiving information on improved rice production technologies. J. Innov. Dev. Strategy, 2011, 5(1): 28-33.

[11] Ekram, M. Z. Adoption of Commonly Used Integrated Pest Management (IPM) Practices By the Boro Rice Growers. M.S. (AEIS) Thesis, Department of Agricultural Extension and Information System, Sher-E-Bangla Agricultural University, Dhaka, 2014.

[12] Kabir, M. F. Adoption of Modern Jute Cultivation Practices by the Farmers of Gaibandha District. M.S. (AEIS) Thesis, Department of Agricultural Extension and Information System, Sher-E-Bangla Agricultural University, Dhaka, 2018.

[13] Mou, M. M. Adoption of Improved Vegetable Cultivation Practices by the Farmers in Selected Areas of Shajahanpur Upazila Under Bogra District. M. S. Thesis (Agricultural Extension and Information System), SAU, Dhaka, 2015.

[14] Hasan, M. Adoption of Modern Practices in Rice Cultivation by The Farmers of Modhukhali Upazila under Faridpur District. M.S. Thesis (Agricultural Extension and Information System), SAU, Dhaka, 2015.

[15] Singh, V. K. and A. Priyadarshi. Extent of Adoption of Improved Practices of Mango Production by Mango Growers in Muzaffarnagar District of Uttar Pradesh. Indian Research Journal of Extension Education, 2010, 10 (3): 107-113.

[16] Rao, D. U. M. and M. K. Singh. 2014. Adoption of Pineapple Cultivation Practices by the Farmers in Manipur State. Indian Research Journal of Extension Education, 14 (1): 111-116.

[17] Mehta, B. M. and M. Sonawane. Entrepreneurial Behaviour of Mango Growers of Valsad District of Gujarat State. Indian Research Journal of Extension Education. 12 (1):30-34.

[18] Chouhan, S. and S. K. R. Singh. 2013. Adoption Dynamics of Improved Sugarcane Cultivation in Madhya Pradesh. Indian Research Journal of Extension Education, 2012, 13 (2): 26-30.

[19] Deshmukh, G. and M. Bariya. Adoption of Recommended Practices of Kharif Groundnut Growers in Saurashtra Zone of Gujarat. Indian Research Journal of Extension Education, 2014, 14 (3): 47-50.

[20] Kabir, M. M. Adoption of Integrated Pest Management (IPM) Practices in Rice Cultivation by the Farmers of Shahjadpur Upazilla under Sirajganj District. M.S. Thesis (Agricultural Extension and Information System), SAU, Dhaka, 2015.

[21] Rahman, M. M. Variables contribution to farmers' attitude towards IPM practices in rice cultivation in Godagari, Rajshahi. Journal of Life Earth Sci. 2010, Vol. 5: 11-15.

[22] Haque, M. S. A Study on the Adoption of Improved Practices in Cultivation in some Selected Areas of Jessore District. MS (Ag. Ext. Ed.) Thesis, Bangladesh Agricultural University, Mymensingh, 1984.

[23] Mohammad, A. A Study on the Farmers Adoption of Insect Control Measures and Related Aspects. M.S. Thesis, Department of Agricultural Extension Education, Bangladesh Agricultural University, Mymensingh, Bangladesh, 1974 